\title{
Comparison of the Performance of Three Cocoa Bean Drying Techniques in Bafia, Southwest Region,
} Cameroon

\author{
Marguerite Belobo Belibi, Judith Van Eijnatten, Charles Kacho Tah, Fidèle Honorine Yobo, Koue A., Nathalie \\ Ewane Nonga, Rachid Hanna, Mary Bakia Moulobe, Léopold Aimé Ndongo, Ntiege Hans Sumelong, and \\ Sylvanus Ngene Nekenja \\ SNV Netherlands Development Organization, Cameroon
}

\begin{abstract}
This research compares the performance of a wood-fuelled oven, a greenhouse solar dryer and open sun drying techniques for drying of fermented cocoa beans, under the same weather conditions. The tests were implemented in Bafia, in the Southwest Region of Cameroon, during the month of November 2017. Performance in drying time (number of days) and quality of the resulting beans were measured (determined using sensory measurements, sight, smell and taste). Data were also collected on the progression of weight and moisture loss in the beans during the drying process, and the ambient temperatures and relative humidity levels of the environment. Also, solar radiation levels were measured for the greenhouse solar dryer and open sun drying techniques. Results showed that during dry weather conditions the wood-fuelled oven was the fastest drying method (1 day), followed by open sun drying (4 days) and the greenhouse solar dryer ( 5 days). The quality of beans produced through open sun drying and in the greenhouse solar dryer had a good colour, and a pleasant chocolate smell and taste. However, the beans from the wood-fuelled oven had an overly dark colour and their smell and taste were smoky due to contamination by smoke from the oven.
\end{abstract}

Keywords: Drying techniques, Bafia, cocoa beans.

\section{Introduction}

In 2012 Cameroon gave itself the year of 2020 to reach the target of producing 600,000 tons of good quality cocoa beans. Table 1 shows the national cocoa production figures over the past 5 seasons and indicates that there is a stagnation of national cocoa bean production at between 210,000 and 240,000 tons/year.

Unless fundamental changes occur in all aspects of cocoa production and post-harvest operations, it seems unlikely that the target of 600,000 tons can be reached by 2020 . The required changes are many and include application of good agricultural and post-harvest practices by farmers. Important post-harvest practices include fermentation, drying and bagging which have

Corresponding author: Sylvanus Ngene Nekenja, Bachelor degree in Project Management, research fields: financing cocoa production \& marketing activities in liberalized economy. to be carried out to a high standard to ensure production and maintaining of high quality cocoa beans. For post-harvest practices, Cameroon has yet to set standards.

Economic and environmental conditions determine the drying techniques applied by cocoa farmers. Common drying techniques include use of wood-fuelled ovens (especially where pluviometry is high) and drying on tarred roads, cemented floors and tarpaulins (on sunny days and in areas receiving relatively more sun and less rain). In Bafia, located in the South-west

Table 1 Cameroon national cocoa production figures between 2012-2103 and 2016-2017.

\begin{tabular}{ll}
\hline Season & National cocoa bean production in tons/year \\
\hline $2012-2013$ & 225,000 \\
$2013-2014$ & 211,000 \\
$2014-2015$ & 232,000 \\
$2015-2016$ & 211,000 \\
$2016-2017$ & 240,000 \\
\hline
\end{tabular}


Region of Cameroon, the main drying technique used is that of the wood-fuelled oven. While there are different types of wood-fuelled ovens, the vast majority of the ovens produce "smoky cocoa". Smoky cocoa is the result of smoke contamination due to leakage of smoke from the oven. Smoky cocoa has a smoky flavour. To remove this flavour manufacturers have to apply a special process before processing the cocoa beans. At the international level, smoky cocoa has resulted in significantly tarnishing the image of cocoa originating from Cameroon.

In recognition of the need to improve the quality of cocoa originating from Cameroon, SNV Cameroun took the initiative of seeking ways to improve post-harvest practices. One initiative was the construction of "Greenhouse Solar Dryers". Under the Cameroon Eco-Cocoa \& ProCISA-CBSC ${ }^{1}$ projects a total of 8 such solar dryers were constructed: 4 in the Centre Region (in Ngomedzap \& Ayos) and 4 in the South-west Region (in Bafia and Konye).

In November 2017, an experiment was conducted to compare the quality of cocoa beans produced through application of three different drying techniques: the greenhouse solar dryer, the wood-fuelled oven and open sun drying on a tarpaulin. This paper describes the experiment and determines the performance of the different drying techniques.

\section{Description of the Three Drying Techniques}

The three drying techniques described in this section are the wood-fuelled oven, open sun drying and the greenhouse solar dryer.

\subsection{The Wood-fuelled Oven}

As mentioned earlier, in the South-west Region in general and in Bafia in particular, WOs(wood-fuelled ovens) are the most common drying technique used by

\footnotetext{
${ }^{1}$ The Cameroon Eco-Cocoa Project was funded by the Dutch Government and implemented in 2014 and 2015. The ProCISA-CBSC project was funded by the German Cooperation and implemented in 2016 and 2017.
}

farmers. This is because the region receives particularly high levels of rainfall, the technology is affordable, timber resources are available, and the technique allows for quick drying.

The WO consists of a tunnel in which wood is burned (see Fig. 1) and an air-filled casing around the tunnel. The heat generated from combustion of the wood travels to the enclosed space around the tunnel through convection. The beans, which spread on a bamboo mat on top of the oven, are dried by the heated air travelling through the mat and the beans spread on top. A good WO will have a chimney to evacuate smoke from the tunnel and thus avoid contamination of the beans; in practice, the chimney may be lacking and contamination by smoke becomes an issue. The WO is mostly applied at the level of individual or a group of households.

Wood is generally obtained from the farm but may also be bought in Bafia. The drying time using this technique is from 18-24 hours for 5 to 6 bags of cocoa beans. When the moisture content of the cocoa beans has reached $9.5 \%{ }^{2}$ the beans are removed from the bamboo mat and transferred to jute bags. In the jute bags, the beans will remain hot for a considerable time longer which allows completion of the drying process.

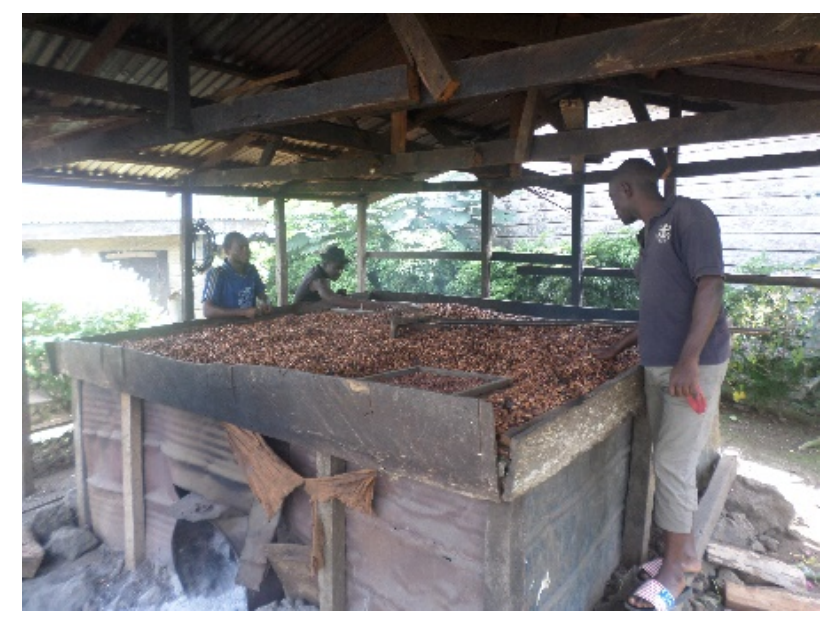

Fig. 1 WO(Wood-fuelled oven) (C) WF

\footnotetext{
2 This is according to the standard set for the WO; in practice, few farmers have equipment to measure the moisture content and they rely on their experience.
} 


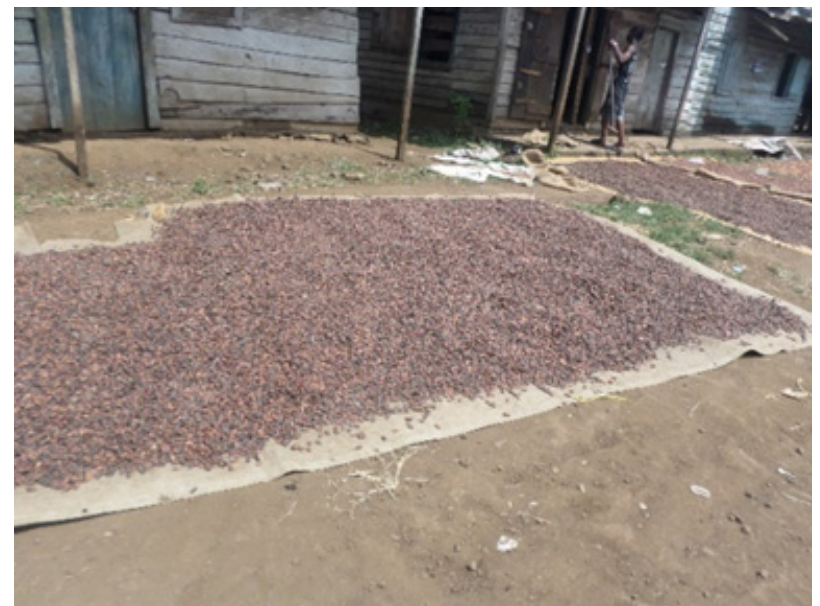

Fig. 2 Open sun drying (C) WF.

\subsection{Open Sun Drying}

OSD (open sun drying) is mainly applied at household level. Under this technique the beans are taken out early in the morning to spread on a tarpaulin or mat near the farmer's house. Throughout the day, a person is present to turn the beans to ensure that they all receive comparable amounts of sunlight. In the evening, the beans are gathered and (ideally) put in jute bags. The next day and following days, the process is repeated until the farmer considers the beans to be $d^{2}{ }^{3}$. Depending on the weather conditions, drying using the OSD technique takes 3 to 5 days.

\subsection{The Greenhouse Solar Dryer}

The GSC (greenhouse solar dryer) technique was brought to Bafia by the SNV under the ProCISA-CBSC project. The GSC design was an adaptation of a model used in Nicaragua where it has proven its effectiveness.

The GSC consists of a wooden frame, the sides of which are covered with translucent UV-resistant plastic film and a roof of translucent corrugated plastic sheets. The floor consists of a layer of gravel. The surface area of the structure measures $10 \times 15$ meters. It is furnished with raised wooden drying boxes giving

\footnotetext{
${ }^{3}$ Few if any farmers have access to equipment to measure moisture content of cocoa beans; therefore, they depend on their own experience.
}

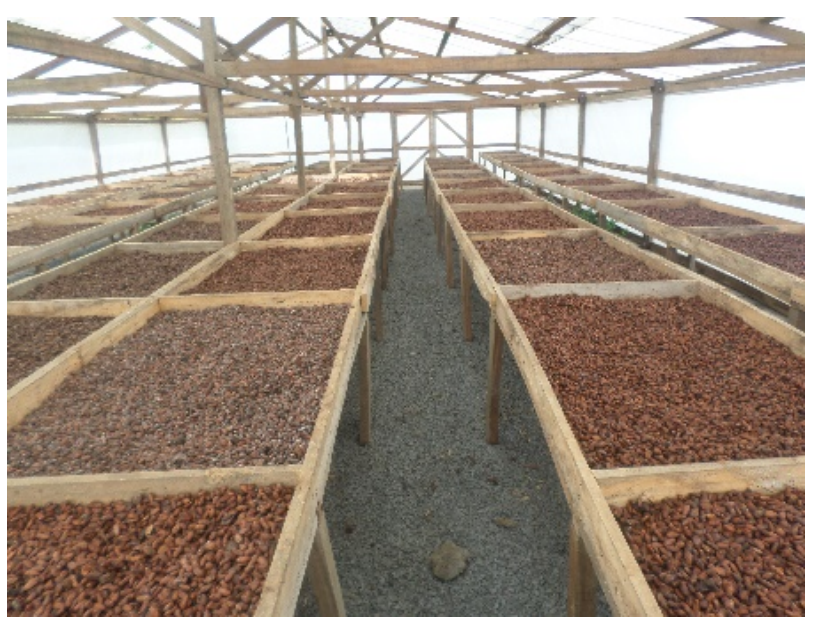

Fig. 3 Greenhouse solar dryer (C) WF.

a drying area of $111 \mathrm{~m}^{2}$. The drying tables are sectioned into 68 compartments (or drying beds) where the beans spread out for drying. Depending on weather conditions, one drying bed dries up to $22 \mathrm{~kg}$ of cocoa beans in 4 to 5 days.

\section{Methodology}

This section presents the methodology of the experiment under separate sections relating to performance indicators and the types of measurements made, equipment used, how overall consistency in the cocoa beans at the start of the experiment was ensured, the sampling method and the measurements taken.

\subsection{Performance Indicators}

The following indicators were used to determine performance of the drying techniques: overall drying time, colour, odour and moisture content of the finished dried bean.

\subsection{Measurements and Data Gathering}

The overall drying time was measured in days while colour and odour of the beans were measured using the senses of sight and smell of three persons who evaluated the beans independently. The beans were considered "dry" when the moisture content measured $8 \%$, the recommended value for cocoa bean moisture content in Cameroon. 
Table 2 Type of measurements and frequency for each drying technique.

\begin{tabular}{llll}
\hline Measurement & Frequency & No. of days & Drying technique \\
\hline Ambient solar radiation & Hourly between 07:00 and 18:00 & 4 days & All 3 techniques \\
Ambient temperature & Hourly between 07:00 and 18:00 & 4 days & All 3 techniques \\
Ambient relative air humidity & Hourly between 07:00 and 18:00 & 4 days & All 3 techniques \\
Cocoa sample drying temperature & Hourly between 07:00 and 18:00 & 4 days & OSD and GSD \\
Cocoa sample weight & Daily between 17:00 and 17:30 & 4 days & OSD and GSD \\
& At the beginning and end of drying & 1 day & WO \\
Cocoa sample moisture content & Daily between 17:00 and 17:30 & 4 days & OSD and GSD \\
Colour & At the beginning and end of drying & 1 day & WO \\
Smokiness (odour) & At the end of the drying process & 1 day & All 3 techniques \\
\hline
\end{tabular}

Measurements were taken of the solar radiation, ambient temperature and relative humidity, as well as the drying temperature, weight and moisture content of the cocoa beans. To ensure that the measurements were comparable, the experiments using the three drying techniques were done in the same place on the same days; thus weather conditions were the same for all three experiments.

Table 2 shows the daily frequency and number of days in which the data were gathered for each drying technique.

\subsection{Equipment Used}

As mentioned earlier, the drying methods used were the WO, OSD and GSD. The WO was located in Bafia town in "Quarter Two", a 10 min motorcycle from Bafia centre. This WO is a typical one for farmers in the Bafia area. It was constructed in December 2016 with private funds (around 300,000 FCFA) but the chimney had already been destroyed. The oven is operational every day, rented by farmers to dry their cocoa beans. On average, the system can dry 2 tons of cocoa beans per week at a cost of 2,000 to 2,500 CFA per bag.

For OSD, a woven plastic bag was used (this material is commonly used by farmers to produce large mats for sun drying). The plastic bag was placed on top of a wooden board to ensure a flat surface. The GSD used was the one located at the Cocoa Business
Service Centre of the cooperative BAFIACOOP. To gather the data, the equipment listed in Table 3 was used.

\subsection{Standardising the Cocoa Beans}

The beans used for this study were purchased from Mr. Yamnyong Jonathan, a registered farmer of the cooperative BAFIAFCOOP. The beans had been fermented using cascade fermentation boxes ${ }^{4}$ located at the CBSC (Cocoa Business Service Centre) of BAFIAFCOOP. By taking beans from the same farmer, who applied "good agricultural practices", and that had been fermented in the same batch using an improved fermentation technique, the maximum possible consistency was ensured.

\subsection{Sampling and Sample Placement}

On Friday night, the 24th of November, between 20:00 and 22:00, the fermented beans to be used in the experiment were removed from the fermentation unit and taken to the GSD where they were placed in the drying beds. On the following Sunday morning, at 07:00, after 33 hours of initial drying, the beans were taken from the same drying bed and divided into samples for subsequent use in the three different drying techniques. Table 4 details the weight and

\footnotetext{
4 Cascade fermentation boxes allow for standardized conditions and are an improved method for cocoa bean fermentation. The fermentation process takes 6 days. The resulting beans are considered "quality cocoa".
} 
Table 3 Equipment and specifications used for data gathering.

\begin{tabular}{|c|c|}
\hline Equipment & Specifications \\
\hline $\begin{array}{l}\text { Relative humidity and } \\
\text { temperature recorder }\end{array}$ & $\begin{array}{l}\text { TROTEC brand with measurement ranges from } 0 \text { to } 100 \% \text { at temperatures } \\
\text { from }-40^{\circ} \mathrm{C} \text { to }+70^{\circ} \mathrm{C} \text {, and an accuracy of } \pm 3.5 \% \text { and } \pm 2.0^{\circ} \mathrm{C}\end{array}$ \\
\hline Solar radiation meter & $\begin{array}{l}\text { VOLTCRAFT brand with a measurement range of } 0 \text { to } 1,999 \mathrm{~W} / \mathrm{m}^{2} \text {, } \\
\text { reading frequency of } 4 / \mathrm{sec} \text { and an accuracy level of } \pm 10 \mathrm{~W} / \mathrm{m}^{2}\end{array}$ \\
\hline Moisture content meter & $\begin{array}{l}\text { DRAMISKI, TWISTGRAIN model, with measurement range for cocoa } \\
\text { from } 6 \% \text { to } 20 \% \text { and accuracy of } \pm 0.5 \% \text { for normalized grain }\end{array}$ \\
\hline Weighing scale & Electronic, with range from $200 \mathrm{~g}$ to $40 \mathrm{~kg}$, graduation of $2 \mathrm{~g}$ \\
\hline
\end{tabular}

Table 4 Number and weight of samples taken, and placement for each drying technique.

\begin{tabular}{lll}
\hline Drying technique & $\begin{array}{l}\text { Sample } \\
\text { (no. and weight) }\end{array}$ & Sample placement \\
\hline Wood-fuelled oven & $\begin{array}{l}\text { 1 sample of } 3 \mathrm{~kg} \\
\text { Open sun drying }\end{array}$ & $\begin{array}{l}\text { The sample was split into two and spread on opposite sides of the bamboo mat } \\
\text { The sample was put on a plastic bag on a wooden board and placed out in the sun }\end{array}$ \\
Greenhouse solar dryer & $\begin{array}{l}\text { 4 samples of } 0.5 \mathrm{~kg} \text { each } \\
\text { For random placement of the 4 samples the GSD was divided into } 4 \text { parts } \\
\text { length-wise, with each part receiving one sample; in its width the GSD was } \\
\text { divided into 2 with each part receiving 2 samples }\end{array}$ \\
\hline
\end{tabular}

number of samples taken and how they were placed for each drying technique.

\section{Results and Discussion}

This section presents the data gathered during the period 26th-29th November 2017 for the GSD and OSD techniques and on 26th November 2017 for the
WO technique. Analyses for the three drying techniques are also presented.

\subsection{Solar Radiation, Ambient Temperature and Relative Humidity}

The hourly data gathered during the 4 days of the experiment were averaged giving the figures 
shown in Table5.

The data were graphed resulting in the graphs shown in Fig. 5.

It must be noted that during the 5 days of the experiment the weather conditions were very good: there was no rain and bright sunshine daily.

The above data show that the solar radiation was highest between 09:00 and 16:00 while the highest temperatures were recorded between 11.00 am and $14.00 \mathrm{pm}$ when they were between 40 and $44^{\circ} \mathrm{C}$. From 09:00 to 11:00 the relative humidity level was below $60 \%$, after which it dropped to $40 \%$ until 14:00 when it rose again but did not pass the $60 \%$ mark until 17:00. This shows that the optimum time for both OSD and GSD, in good weather conditions, is between 09:00 and 17:00.
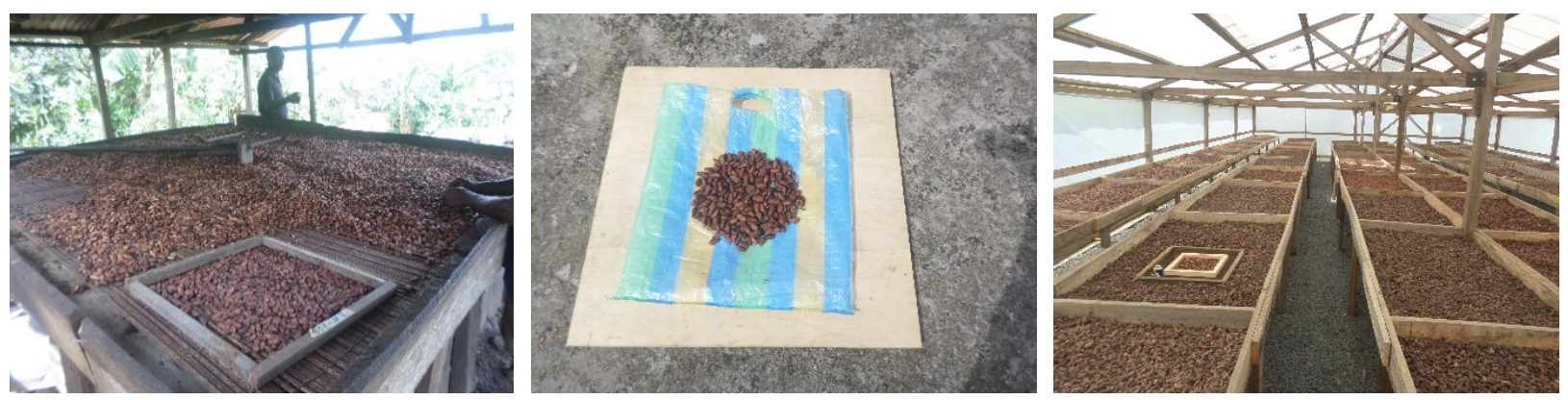

Fig. 1 Placement of samples on the WO, OSD and GSD.

Table 5 Average solar radiation, temperature and relative humidity at hourly intervals between 07.00 and 18.00

\begin{tabular}{llll}
\hline Time $[\mathrm{h}: \mathrm{m}]$ & Average solar radiation $\left[\mathrm{W} / \mathrm{m}^{2}\right]$ & Average temperature $\left[{ }^{\circ} \mathrm{C}\right]$ & Average relative humidity $[\%]$ \\
\hline $07: 00$ & 77.77 & 22.07 & 91.03 \\
$08: 00$ & 146.20 & 27.87 & 75.87 \\
$09: 00$ & 154.28 & 32.93 & 62.88 \\
$10: 00$ & 155.50 & 37.18 & 52.88 \\
$11: 00$ & 155.90 & 40.65 & 43.95 \\
$12: 00$ & 156.05 & 42.95 & 38.68 \\
$13: 00$ & 155.70 & 42.80 & 37.33 \\
$14: 00$ & 155.20 & 44.03 & 35.78 \\
$15: 00$ & 154.38 & 40.53 & 42.33 \\
$16: 00$ & 154.05 & 36.68 & 50.03 \\
$17: 00$ & 127.93 & 32.63 & 59.95 \\
$18: 00$ & 8.55 & 28.60 & 73.93 \\
\hline
\end{tabular}
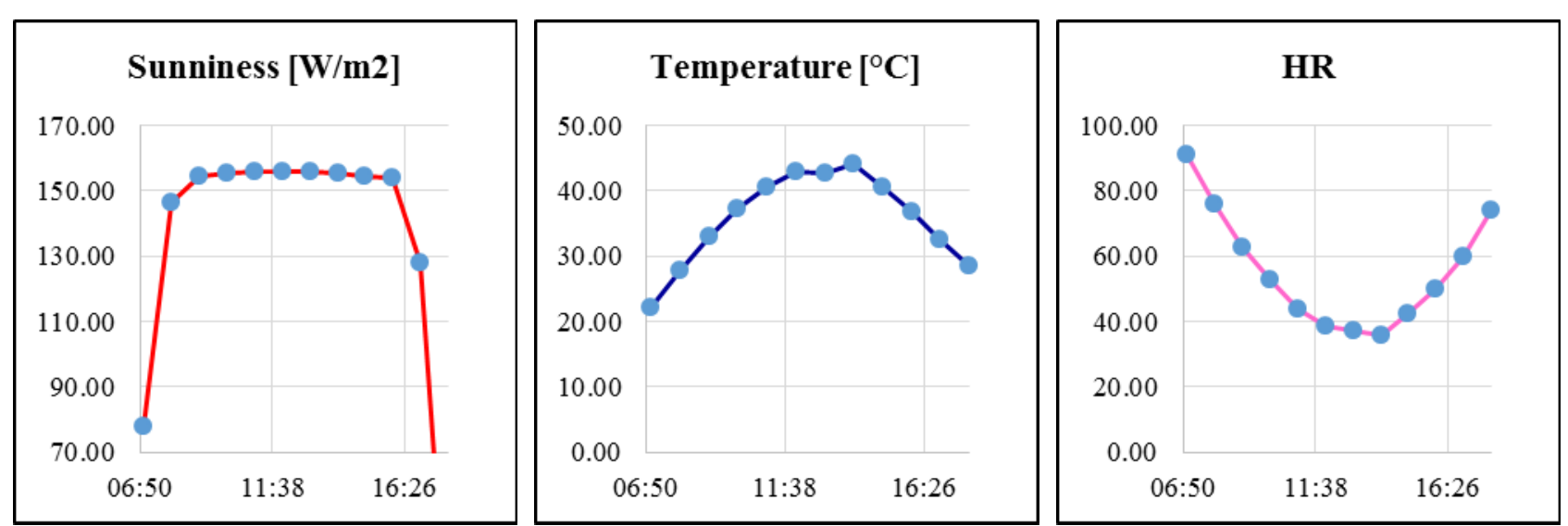

Fig. 5 Graphs showing average solar radiation, temperature and relative humidity at hourly intervals between 07:00 and 18:00 during the period 26-29 November 2017. 


\subsection{Drying Temperatures and Relative Humidity for the GSD and OSD Techniques}

Table 6 gives the average hourly drying temperature and average relative humidity of the samples of the OSD and GSD techniques between 07:00 and 18:00.

The data show that OSD reaches $40-44^{\circ} \mathrm{C}$ in the middle of the day while the GSD reaches only $39^{\circ} \mathrm{C}$. Lowest relative humidity was measured at 14:00, for OSD the measurement was $35 \%$, for the GSD it was $46 \%$.

\subsection{Daily Weight and Moisture Content of the Samples}

Table 7 summarizes the average daily weight and moisture content of the samples.

The data show that it took the GSD 5 days to reach the $8-9 \%$ moisture content needed for quality cocoa but only 4 days for the OSD. The data also show that cocoa beans lose water quicker using the OSD than the GSD. However, the WO is the fastest method. Even though the result for all the techniques was $<9 \%$ of cocoa bean moisture content, the loss in weight was not the same for the three drying techniques. The WO technique resulted in a weight loss of $28 \%$, while the GSD and OSD resulted in a significantly higher weight loss at around $40 \%$.

\subsection{Comparing Measurements for the Three Drying Techniques}

In this section the progression of moisture content and weight are compared as well as the drying temperatures and relative humidity of the air.

4.4.1 Evolution of Cocoa Bean Moisture Content and Weight

The graphs below compare the weight and moisture content of samples in the three drying techniques during the five days of the experiment.

The weight and moisture curves exhibit the same trends. Both parameters decrease during the drying

Table 6 GSD and OSD average hourly drying temperature and relative humidity.

\begin{tabular}{lllll}
\hline \multirow{2}{*}{ Time } & \multicolumn{3}{c}{ GSD } & OSD \\
\cline { 2 - 5 } & Temperature $\left({ }^{\circ} \mathrm{C}\right)$ & RH $(\%)$ & Temperature $\left({ }^{\circ} \mathrm{C}\right)$ & RH $(\%)$ \\
\hline $07: 00$ & 21.93 & $93.8 \%$ & 22.07 & $91.0 \%$ \\
$08: 00$ & 26.53 & $83.3 \%$ & 27.87 & $75.9 \%$ \\
$09: 00$ & 32.43 & $67.4 \%$ & 32.93 & $62.9 \%$ \\
$10: 00$ & 34.59 & $62.5 \%$ & 37.18 & $52.9 \%$ \\
$11: 00$ & 37.04 & $54.4 \%$ & 40.65 & $44.0 \%$ \\
$12: 00$ & 38.29 & $50.4 \%$ & 42.95 & $38.7 \%$ \\
$13: 00$ & 39.44 & $46.5 \%$ & 42.80 & $37.3 \%$ \\
$14: 00$ & 39.04 & $46.5 \%$ & 44.03 & $35.8 \%$ \\
$15: 00$ & 37.53 & $49.4 \%$ & 40.53 & $42.3 \%$ \\
$16: 00$ & 35.38 & $55.7 \%$ & 36.68 & $50.0 \%$ \\
$17: 00$ & 32.37 & $62.8 \%$ & 32.63 & $60.0 \%$ \\
$18: 00$ & 28.99 & $73.0 \%$ & 28.60 & $73.9 \%$ \\
\hline
\end{tabular}

Table 7 GSD, OSD and WO average daily weight and moisture content of the samples.

\begin{tabular}{lllllll}
\hline \multirow{2}{*}{ Day } & \multicolumn{3}{c}{ GSD } & OSD & WO \\
\cline { 2 - 7 } & Weight $(\mathrm{kg})$ & Moisture (\%) & Weight $(\mathrm{kg})$ & Moisture $(\%)$ & Weight $(\mathrm{kg})$ & Moisture $(\%)$ \\
\hline Day 1 & 0.500 & $>20 \%$ & 0.500 & $>20 \%$ & 3.000 & $>20 \%$ \\
Day 2 & 0.405 & $18.5 \%$ & 0.396 & $14.4 \%$ & 2.160 & $9.0 \%$ \\
Day 3 & 0.340 & $12.9 \%$ & 0.328 & $10.1 \%$ & - & - \\
Day 4 & 0.311 & $11.4 \%$ & 0.312 & $8.2 \%$ & - & - \\
Day 5 & 0.295 & $8.6 \%$ & 0.304 & $7.2 \%$ & - & - \\
\hline
\end{tabular}




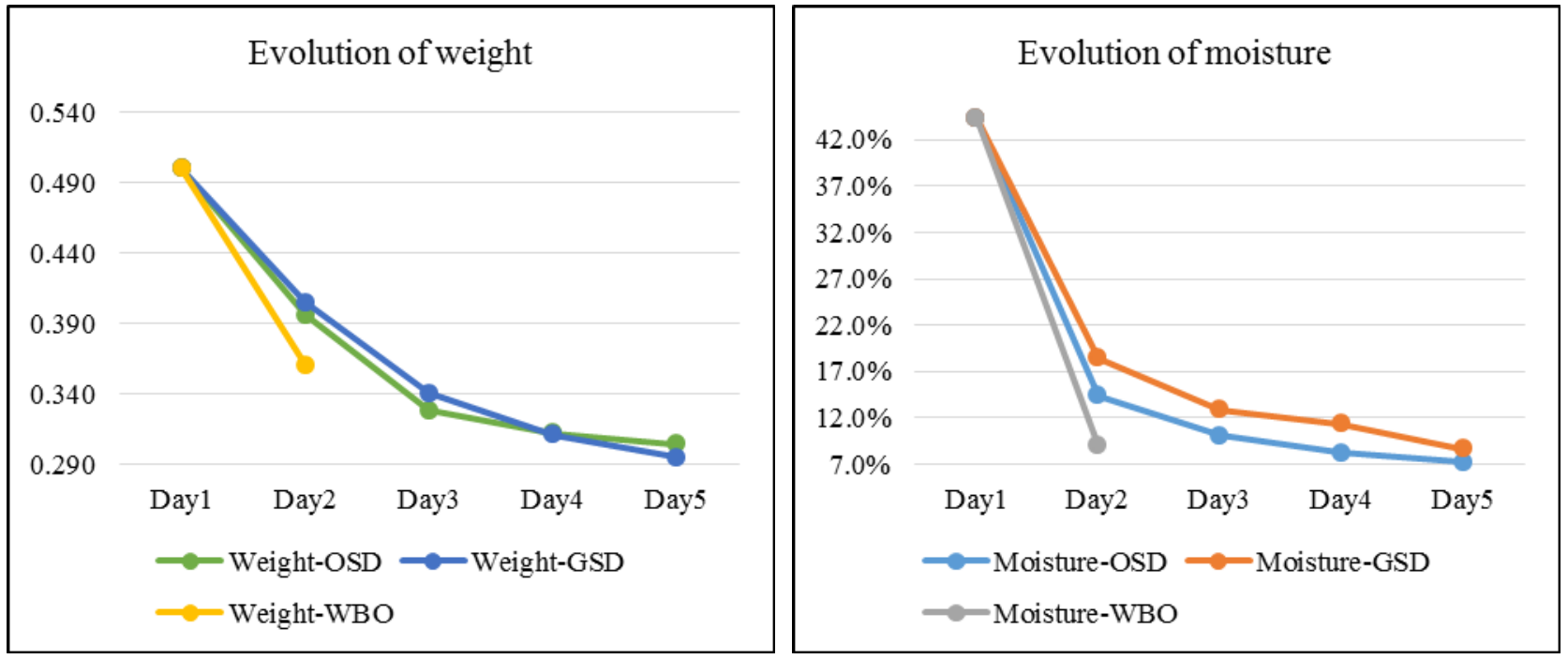

Fig. 6 Graphs showing the evolution of the weight and moisture content of the samples.
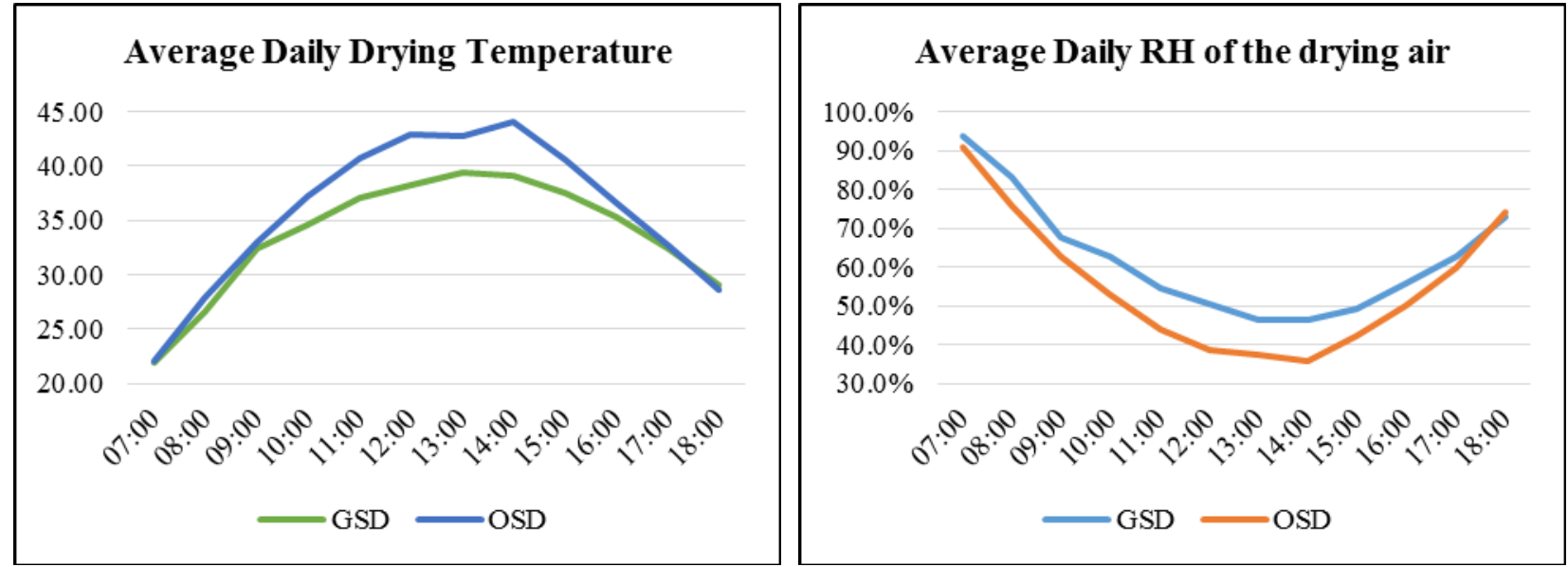

Fig. 7 Graphs of average daily drying temperature and relative humidity of the samples.

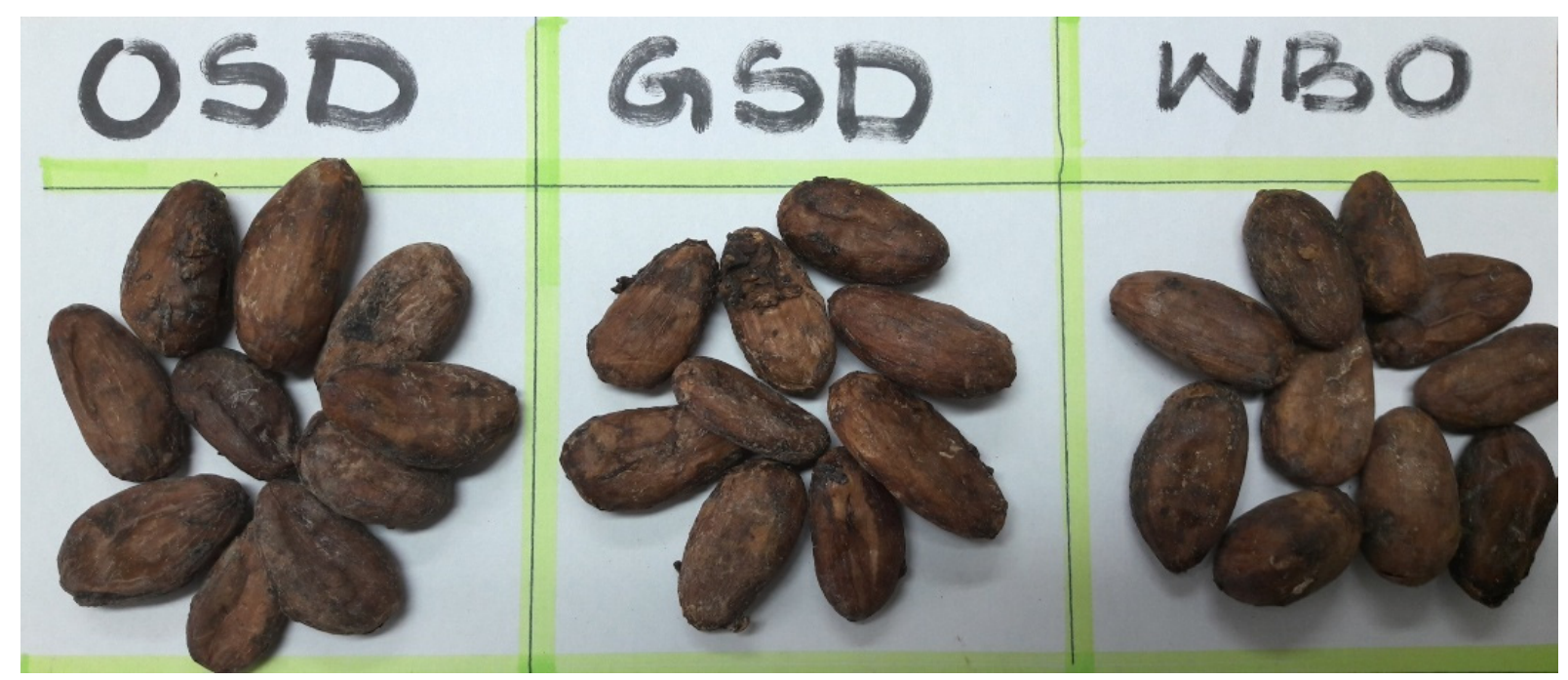

Fig. 8 External appearance of samples from OSD, GSD and WBO. 
process irrespective of the drying technique. Cocoa in the WO dries fastest, followed by cocoa in the OSD technique, the GSD taking a little longer. The loss in weight was calculated to be $28 \%, 41 \%$ and $39 \%$ respectively for the WO (after 1 day), OSD (4 days) and GSD (5 days). The WO took less than a day to dry the beans to $9 \%$ moisture content, whereas the drying durations to reach a similar level of moisture content were 4 days for the OSD and 5 days for the GSD.

It is possible that the difference observed in drying duration between the GSD and OSD can be explained by the fact that cocoa beans in the solar dryers are exposed to a higher relative humidity of the air, approaching $100 \%$ when the drying process stagnates. However, OSD beans are taken indoors at 17:30 pm till 7:00 am the next day, avoiding the rising humidity outside at night and benefitting from the lower humidity indoors..

4.4.2 Evolution of Cocoa Bean Drying Temperature and Relative Humidity

The graphs below compare the average ambient drying temperature and relative humidity of samples in the OSD and GSD.

The ambient drying temperature and relative humidity exhibit opposite trends. Temperature and relative humidity are respectively higher and lower for the OSD technique. This explains why the drying duration is shorter for the OSD technique than the GSD technique.

For both the OSD and GSD, the drying temperatures do not exceed $45^{\circ} \mathrm{C}$ unlike the WO where the drying temperature reached above $60^{\circ} \mathrm{C}$. With a higher temperature, the drying process is faster but results in poor cocoa quality because at drying temperatures above $60^{\circ} \mathrm{C}$, cocoa beans become acid (reduced $\mathrm{pH}$ and high free acidity level).

\subsection{External Appearance, Smell and Taste of the Beans}

The colour and external appearance of the beans differed for each drying technique used: the WO produced a darker bean, the GSD a lighter bean and the OSD a bean with colour in between the two others.

Beans from the OSD and GSD had a chocolate aroma whereas the beans from the WO had a smoky odour. The three evaluators independently reached the same conclusions.

\section{Conclusion}

The purpose of this study was to determine the performance of three drying techniques used for fermented cocoa beans in Bafia, under the same weather conditions. The performance indicators were: drying time (in days) and quality of the resulting bean measured in colour, odour and flavour.

The WO was the fastest drying technique (1 day) but produced a poor quality bean (overly dark in colour and smoky in smell and taste). Under the same good weather conditions the OSD took 4 days to produce a good quality bean while the GSD took 5 days. Both the OSD and GSD produced beans of the right colour and without a smoky odour and flavour.

In Bafia, which receives high annual rainfall levels (3,500-4.000 mm), weather conditions are often not favourable for sun drying. Therefore, the greenhouse solar dryer, which still functions on rainy days, is a good solution for farmers to be used in combination with OSD. An additional advantage of the GSD is that it does not require a family in constant attendance to turn the beans (this is taken care of by the personnel of the GSD).

To further test the performance of the cocoa drying techniques it would be interesting to repeat the experiment:

- Under different weather conditions (e.g., under different levels of cloud cover and during intermittent rain);

- In different cocoa producing areas where weather conditions are different;

- Determine bean quality through other than the rather subjective sensory measurements (e.g., through chemical analyses). 
After installation of a forced ventilation system in the GSD to evacuate humid air, thereby we can improve drying efficiency and reduce the drying time.

\section{References}

[1] Accessed on 10/12/2017, https://www.statista.com/ statistics/263855/cocoa-bean-production-worldwide-by-r egion/.

[2] Tagro Simplice Guehi et al. 2010. "Performance of different drying methods and their effects on the chemical quality attributes of raw cocoa material.” International Journal of Food Science and Technology 45: 1564-1571. Accessed 19/12/2017. http://www2.hcmuaf.edu.vn/ data/lhquang/file/Cocoa/Performence $\% 20$ of $\% 20$ different \%20drying\%20methods.pdf.

[3] Irie, G., and Zahouli, B. et al., 2010. "Effect of Drying Methods on the Chemical Quality, Traits of Cocoa Raw Material." Advance Journal of Food Science and Technology 2 (4): 184-190. Accessed 19/12/2017. http://maxwellsci.com/print/ajfst/v2-184-190.pdf. 